\title{
Assessment of Genetic Variability and Correlation of Yield Components of Elite Rice Genotypes (Oryza sativa L.)
}

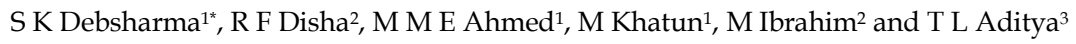

ABSTRACT

\begin{abstract}
The study was conducted to evaluate the extent of variability among the elite rice (Oryza sativa L.) genotypes for yield and yield components. Sixteen elite rice genotypes were evaluated for yield and yield contributing characters in Bangladesh Rice Research Institute, Regional Station, Satkhira. Highest grain yield $\left(\mathrm{t} \mathrm{ha}{ }^{-1}\right)$ was observed in BR(Bio)8333-BC5-2-16, which was followed by BR16, BRRI dhan28, BRRI dhan58 and BRRI dhan29. BR7671-37-2-2-37-3-P3 had the highest number of grains per panicle with minimum thousand grain weight. Correlation analysis revealed that the number of panicles per plant (0.301), days to $50 \%$ flowering (0.606) and grain yield per plant (0.393) had the significantly positive contribution to grain yield. After evaluation of yield components, four genotypes namely BR(Bio)8333-BC5-1-20, BR(Bio)8333-BC5-2-16, BR(Bio)8333BC5-2-22 and BR(Bio)8333-BC5-3-10 were selected as outstanding genotypes, which can be used as potential breeding materials for variety development or in the crossing program to enrich the rice gene pool in Bangladesh.
\end{abstract}

Key words: Variability, correlation, yield components, elite rice genotypes.

\section{INTRODUCTION}

Rice (Oryza sativa L.) is one of the pivotal staple cereal crops feeding more than half of the world population. In view of the growing population, the basic objective of the plant breeders would always be towards yield improvement of staple food crops. Sufficient rice production is the key to ensure food security in Bangladesh. In fact, 'Rice security' is synonymous to 'Food security' in Bangladesh as in many other rice growing countries (Brolley, 2015). Rice security is not just an economic issue but also an important parameter for determining social and political stability (Nath, 2015). More food will be required in future because of increasing population. Population of Bangladesh will reach 215.4 million in 2050, when 44.6 MT of clean rice will be needed (Kabir et al., 2015). Theoretically, rice still has great yield potential to be tapped and there are many ways to raise rice yield, such as building of irrigation works, improvement of soil conditions, agronomic management techniques and breeding of high yielding varieties. The knowledge on the nature and magnitude of genetic variation in respect of quantitative characters like yield and its components is essential for effective crop improvement. Selection of high yielding varieties based only on grain yield will not be much effective unless adequate information on genetic parameters and association between them are available to formulate hybridization and selection program for further improvement, because the estimate of the mean serves as a basis for eliminating the undesirable genotypes.

Information on correlations of characters, direct and indirect effects contributed by each character towards yield will be an added advantage in aiding the selection process. Correlation establishes the extent of association between yield and its components and also brings out relative importance of their effects, thus giving an obvious understanding of their association with grain yield.

\footnotetext{
1Plant Breeding Division, Bangladesh Rice Research Institute, Gazipur-1701, Bangladesh, 2Bangladesh Rice Research Institute, Regional Station, Satkhira-9400, Bangladesh, ${ }^{3}$ Director (Research), Bangladesh Rice Research Institute, Gazipur1701, Bangladesh.

*Corresponding author's E-mail: sanjoybrri@gmail.com
} 
Ultimately, this kind of analysis could help the breeder to design his selection strategies to improve grain yield. Therefore, the present investigation is carried out with the objective of studying the analysis and character associations in rice genotypes for yield improvement.

\section{MATERIALS AND METHODS}

Sixteen elite rice genotypes including five standard check varieties namely, BR16, BRRI dhan28, BRRI dhan58 and BRRI dhan29 were grown at Bangladesh Rice Research Institute, Regional Station, Satkhira, Bangladesh during Boro season 2016-17. The experiment was laid out in a Randomized Complete
Block Design with three replications. Seeding was done on 09 December 2016 and 35 days old seedlings were transplanted. Twenty $\mathrm{cm}$ distance was maintained between the rows and $15 \mathrm{~cm}$ between the plants. Single seedling was used for transplanting and unit plot size was $10.2 \mathrm{~m}^{2}$. TSP and MOP were applied at the rate of $100 \mathrm{~kg} / \mathrm{ha}$ and 120 $\mathrm{kg} / \mathrm{ha}$, respectively during final land preparation. Urea was applied at the rate of $260 \mathrm{~kg} / \mathrm{ha}$ in three splits at 10 and 30 days after transplanting and 5 days before panicle initiation. A hand weeding was done at 25 days after transplanting. Others intercultural operations and pest control measures were done as and when necessary.

Table 1. Genotypes with passport data are used for this study.

\begin{tabular}{llll}
\hline Code & Genotype & Parentage & Source \\
\hline GEN1 & BR(Bio)8333-BC5-1-1 & BRRI dhan29/IRBB60 & BRRI \\
GEN2 & BR(Bio)8333-BC5-1-20 & BRRI dhan29/IRBB60 & BRRI \\
GEN3 & BR(Bio)8333-BC5-2-16 & BRRI dhan29/IRBB60 & BRRI \\
GEN4 & BR(Bio)8333-BC5-2-22 & BRRI dhan29/IRBB60 & BRRI \\
GEN5 & BR(Bio)8333-BC5-3-10 & BRRI dhan29/IRBB60 & BRRI \\
GEN6 & BRC266-5-1-1-1 & BR16/90060-TR1252-8-2-1 & BRRI \\
GEN7 & BRC266-5-1-2-1 & BR16/90060-TR1252-8-2-1 & BRRI \\
GEN8 & BR8523-36-2-2-6 & IR 77512-128-2-1-2 / BR 6817-25-2-2 & BRRI \\
GEN9 & BR16 (Ck.) & IR1416-131-5/IR1364-37-3-1//IR1544A-E666 & BRRI \\
GEN10 & BR7671-37-2-2-37-3-P3 & BRRI dhan29/ IR68144 & BRRI \\
GEN11 & BR8626-19-5-1-2 & BR7166-5B-6/ SHEW WAR TUN// BRRI dhan47 & BRRI \\
GEN12 & BR8626-10-5-1 & BR7166-5B-6/ SHEW WAR TUN// BRRI dhan47 & BRRI \\
GEN13 & BR8109-29-2-2-3 & BM9821/Parija & BRRI \\
GEN14 & BRRI dhan28 (Ck.) & BR6 (IR28)/Purbachi & BRRI \\
GEN15 & BRRI dhan58 (Ck.) & Somaclonal line of BRRI dhan29 & BRRI \\
\hline
\end{tabular}

Source: BRRI (2013) and BRRI (2019). 


\section{Data collection of agronomic traits}

Data were collected at days to 50\% flowering, plant height $(\mathrm{cm})$, number of tillers per plant, number of panicles per plant, grains per panicle, grain yield per plant, panicle length (cm), thousand-grain weight (g), fertility (\%) and yield ( $\left.\mathrm{t} \mathrm{ha}^{-1}\right)$. Days to flowering has been recorded as soon as $50 \%$ of the panicles appeared. Five plants were randomly selected excluding the border rows and avoiding the missing hills around for recording data on plant height in centimeter. Numbers of tillers were recorded in maximum tillering stage. The plant height was measured from ground level to tip of the tallest panicle excluding awns. Panicles were harvested from each individual plant at maturity, properly labelled and placed in net bags separately and air-dried at room temperature for one week. Percentages of spikelet fertility, thousand grain-weight and grain yield per plot were estimated by given formula:

$$
\begin{gathered}
\text { Spikelet fertility }(\%)=\frac{\text { Number of filled grains }}{\text { Number of filled grains }+ \text { number of unfilled grains }} \times 100 \\
\text { Yield }(\mathrm{t} / \mathrm{ha})=\frac{100-\text { Grains moisture content }(\%)}{100-14} \times \text { Plot yield }
\end{gathered}
$$

\section{Statistical Analysis}

Genotypic variance, mean comparisons of different traits, coefficient of variation (CV) was measured by STAR software (version 2.0.1) and PB Tools software (version 1.3). Analysis of variance was used to test the significance of variance sources, while Tukey's Honest Significant Difference (HSD) test $(\mathrm{p}=$ 0.05) was employed to compare the differences among treatment means. The correlation coefficient analysis was conducted to find the relationship of different traits.

\section{RESULTS}

\section{Genetic variability}

The analysis of variance shows highly significant genetic variations $(P \leq 0.01)$ among the genotypes for days to $50 \%$ flowering, plant height, number of tillers per plant, number of panicles per plant, number of grains per panicle, grain yield per plant, panicle length, thousand-grain weight, grain fertility and grain yield (Table 2). Coefficient of variation (CV) for days to $50 \%$ flowering, plant height, number of tillers per plant, number of panicles per plant, number of grains per panicle, grain yield per plant, panicle length, thousand-grain weight, grain fertility and grain yield were $0.92,2.42,7.11,14.07,12.93,5.33,4.40,12.92$, 6.75 and $4.35 \%$ respectively (Table 2 ).

It was observed that mean values for the studied traits ranged from 105 to 120 days for days to $50 \%$ flowering, 88.6 to 116.3 $\mathrm{cm}$ for plant height, 8 to 14.3 for number of tillers per plant, 8.4 to 15.4 for number of panicles per plant, 158.6 to 299 for number of grains per panicle, 19.7 to $27.7 \mathrm{~g}$ for grain yield per plant, 21.3 to $25.6 \mathrm{~cm}$ for panicle length, $16.1 \mathrm{~g}$ to $24.7 \mathrm{~g}$ for thousand grain weight, 69.4 to 85.7 for grain fertility and 5.18 to $7.58 \mathrm{t} \mathrm{ha}^{-1}$ for grain yield (Table 3). The highest and the lowest yield was observed in GEN1 (BR (Bio) 8333-BC5-1-1) and GEN8 (BR8523-36-2-2-6), respectively. On the other hand, the longest days to $50 \%$ flowering was found in GEN1 (BR(Bio)8333BC5-1-1) (120 days) and the earlier days to $50 \%$ flowering was found in GEN8 (BR852336-2-2-6) that was 105 days. Figure 1 shows comparison between days to $50 \%$ flowering 
and yield ( $t$ ha-1) of four selected outstanding genotypes along with the check varieties. Among the genotypes, GEN2 (BR(Bio)8333BC5-1-20), GEN3 (BR(Bio)8333-BC5-2-16), GEN4 (BR(Bio)8333-BC5-2-22) and GEN5 (BR(Bio)8333-BC5-3-10) produced 0.84 to
$1.67 \mathrm{t} \mathrm{ha}^{-1}, \quad 0.92$ to $1.75 \mathrm{t} \mathrm{ha}^{-1}, 0.82$ to 1.65 $\mathrm{t}$ ha ${ }^{-1}$ and 0.79 to $1.62 \mathrm{t} \mathrm{ha}^{-1}$ higher compared to the check varieties BR16 (6.56 $\left.\mathrm{t} \mathrm{ha}^{-1}\right)$, BRRI dhan28 (5.83 t ha-1), BBRI dhan58 (6.66 t ha-1) and BRRI dhan29 (6.21 $\left.\mathrm{t} \mathrm{ha}^{-1}\right)$, respectively (Fig. 1).

Table 2. Genotypic variations of the yield contributing traits in 16 rice genotypes.

\begin{tabular}{llllllllllll}
\hline $\begin{array}{l}\text { Source of } \\
\text { variation }\end{array}$ & DF & $50 \mathrm{~F}$ & PH & TILL & PP & GP & GYP & PL & TGW & F (\%) & Yd \\
\hline Genotype & 15 & $60.2^{* *}$ & $129.6^{* *}$ & $12.1^{* *}$ & $12.7^{* *}$ & $6596.6^{* *}$ & $19.2^{* *}$ & $4.4^{* *}$ & $13.9^{* *}$ & $87.7^{* *}$ & $1.67^{* *}$ \\
Rep & 2 & $0.3^{\mathrm{NS}}$ & $16.6^{\mathrm{NS}}$ & $2.1^{\mathrm{NS}}$ & $1.5^{\mathrm{NS}}$ & $1234.8^{\mathrm{NS}}$ & $0.5^{\mathrm{NS}}$ & $1.8^{\mathrm{NS}}$ & $25.5^{\mathrm{NS}}$ & $18.6^{\mathrm{NS}}$ & $0.1^{\mathrm{NS}}$ \\
Error & 30 & 1.1 & 6.1 & 0.6 & 2.8 & 908.2 & 1.6 & 1.1 & 6.7 & 28.5 & 0.1 \\
\hline Mean & & 114.0 & 102.3 & 11.0 & 11.8 & 233.2 & 23.4 & 23.6 & 20.1 & 79.2 & 6.7 \\
CV\% & & 0.92 & 2.42 & 7.11 & 14.07 & 12.93 & 5.33 & 4.40 & 12.92 & 6.75 & 4.35 \\
\hline
\end{tabular}

** indicate significantly different at $1 \%, \mathrm{NS}=$ Non significance. $\mathrm{CV}$ denote co-efficient of variation. Indicators: $50 \mathrm{~F}=\mathrm{days}$ to $50 \%$ flowering, $\mathrm{PH}=$ plant height $(\mathrm{cm}), \mathrm{TILL}=$ number of tillers per plant, $\mathrm{PP}=$ number of panicles per plant, $\mathrm{GP}=$ grains per panicle, GYP= grain yield per plant $(\mathrm{g}), \mathrm{PL}=$ panicle length $(\mathrm{cm})$, $\mathrm{TGW}=$ thousand grain weight $(\mathrm{g})$, F $(\%)=$ fertility $(\%)$ and $\mathrm{Yd}=$ yield $\left(\mathrm{t} \mathrm{ha}^{-1}\right)$.

Table 3. Mean comparison of different traits of the genotypes through Tukey's Honest Significant Difference (HSD).

\begin{tabular}{|c|c|c|c|c|c|c|c|c|c|c|}
\hline Code & $50 \mathrm{~F}$ & $\mathrm{PH}$ & TILL & PP & GP & GYP & PL & TGW & $\mathrm{F}(\%)$ & $\mathrm{Yd}$ \\
\hline GEN1 & $120 \mathrm{a}$ & 102.3ce & $9.6 \mathrm{gh}$ & $11.8 \mathrm{a}-\mathrm{d}$ & 225.6a-f & 20.8ef & 22.9a-d & $18.7 \mathrm{ab}$ & $83.0 \mathrm{ab}$ & $7.10 a-c$ \\
\hline GEN2 & $117 a b$ & $104.3 \mathrm{~b}-\mathrm{d}$ & $9.3 \mathrm{~g}-\mathrm{i}$ & 11.1a-d & $215.0 \mathrm{~b}-\mathrm{f}$ & $21.8 \mathrm{~d}-\mathrm{f}$ & 23.3a-d & 20.1ab & $83.5 \mathrm{ab}$ & $7.50 \mathrm{ab}$ \\
\hline GEN3 & $116 b c$ & $102.0 c-e$ & $9.3 \mathrm{~g}-\mathrm{i}$ & $11.8 a-d$ & $204.3 \mathrm{c}-\mathrm{f}$ & $22.0 \mathrm{~d}-\mathrm{f}$ & 23.0a-d & $20.5 \mathrm{ab}$ & $83.1 \mathrm{ab}$ & $7.58 \mathrm{a}$ \\
\hline GEN4 & $118 \mathrm{ab}$ & $106.3 \mathrm{bc}$ & $8.0 \mathrm{i}$ & 13.2a-d & 227.0a-f & $22.1 \mathrm{~d}-\mathrm{f}$ & 23.6a-d & $21.2 \mathrm{ab}$ & $81.9 \mathrm{ab}$ & 7.48ab \\
\hline GEN5 & $117 \mathrm{ab}$ & $111.0 \mathrm{ab}$ & $9.3 \mathrm{~g}-\mathrm{i}$ & $15.1 \mathrm{ab}$ & 271.0a-e & $21.9 \mathrm{~d}-\mathrm{f}$ & $23.7 \mathrm{a}-\mathrm{d}$ & $18.8 \mathrm{ab}$ & $81.6 a b$ & $7.45 \mathrm{ab}$ \\
\hline GEN6 & 110de & 104.6bd & $12.6 \mathrm{~b}-\mathrm{d}$ & $8.4 \mathrm{~d}$ & $158.6 f$ & 25.2a-d & $25.6 \mathrm{a}$ & $21.5 \mathrm{ab}$ & $70.2 \mathrm{ab}$ & $6.51 \mathrm{c}-\mathrm{e}$ \\
\hline GEN7 & $112 d$ & $95.6 \mathrm{e}-\mathrm{g}$ & $14.0 \mathrm{ab}$ & $10.2 b-d$ & 186.6e-f & 23.8b-e & $24.6 a-c$ & 18.1ab & $76.3 \mathrm{ab}$ & $6.40 c-e$ \\
\hline GEN8 & $105 \mathrm{~g}$ & $116.3 a$ & 8.6hi & $10.2 b-d$ & 195.6d-f & $19.7 \mathrm{f}$ & $24.6 a-c$ & 19.9ab & $74.7 \mathrm{ab}$ & $5.18 \mathrm{~g}$ \\
\hline GEN9 & $118 a b$ & $92.3 \mathrm{fg}$ & $14.3 \mathrm{a}$ & $8.9 \mathrm{~cd}$ & $171.3 \mathrm{f}$ & 24.7a-d & 23.5a-d & $24.7 \mathrm{a}$ & $78.2 \mathrm{ab}$ & 6.58ce \\
\hline GEN10 & $113 \mathrm{~cd}$ & $102.6 c-e$ & $12.0 \mathrm{c}-\mathrm{e}$ & 13.1a-d & $299.0 \mathrm{ab}$ & 20.5ef & 23.5a-d & $16.1 \mathrm{~b}$ & 77.3a-d & $5.40 \mathrm{fg}$ \\
\hline GEN11 & 112de & $98.6 \mathrm{~d}-\mathrm{f}$ & $11.3 \mathrm{~d}-\mathrm{f}$ & $13.8 \mathrm{a}-\mathrm{c}$ & $287.0 \mathrm{a}-\mathrm{d}$ & $27.2 \mathrm{ab}$ & 23.9a-d & $20.5 a b$ & $85.5 \mathrm{a}$ & $7.10 a-c$ \\
\hline GEN12 & $116 \mathrm{bc}$ & $88.6 \mathrm{~g}$ & $10.6 \mathrm{e}-\mathrm{g}$ & $10.6 \mathrm{a}-\mathrm{d}$ & 219.3b-f & $26.8 \mathrm{a}-\mathrm{c}$ & $21.3 \mathrm{~d}$ & $23.0 \mathrm{ab}$ & 77.6a-d & $7.06 a-c$ \\
\hline GEN13 & $113 \mathrm{~cd}$ & $104.6 \mathrm{~b}-\mathrm{d}$ & 13.3a-c & $15.4 \mathrm{a}$ & $288.0 \mathrm{a}-\mathrm{c}$ & $27.7 \mathrm{a}$ & 24.1a-d & $16.9 \mathrm{ab}$ & $72.5 \mathrm{~cd}$ & $7.19 a-c$ \\
\hline GEN14 & $106 f g$ & $102.3 c-e$ & $10.3 \mathrm{fg}$ & $10.2 b-d$ & 225.3a-f & $21.5 \mathrm{~d}-\mathrm{f}$ & $21.6 \mathrm{~cd}$ & $20.8 a b$ & $85.7 a$ & $5.83 \mathrm{e}-\mathrm{g}$ \\
\hline GEN15 & $109 \mathrm{ef}$ & 102.0c-e & $10.3 \mathrm{fg}$ & 13.3a-d & $315.6 a$ & $26.0 \mathrm{a}-\mathrm{c}$ & $22.4 b-d$ & $20.0 \mathrm{ab}$ & $85.3 a$ & $6.66 \mathrm{~b}-\mathrm{e}$ \\
\hline GEN16 & $118 \mathrm{ab}$ & $103.3 \mathrm{~cd}$ & $13.3 a-c$ & 11.4a-d & 240.6a-f & $23.3 \mathrm{c}-\mathrm{f}$ & $25.4 \mathrm{ab}$ & $20.0 \mathrm{ab}$ & $69.4 \mathrm{~d}$ & $6.21 \mathrm{~d}-\mathrm{f}$ \\
\hline Maxi. & 120 & 116.3 & 14.3 & 15.4 & 299.0 & 27.7 & 25.6 & 24.7 & 85.7 & 7.58 \\
\hline Mini. & 105 & 88.6 & 8.0 & 8.4 & 158.6 & 19.7 & 21.3 & 16.1 & 69.4 & 5.18 \\
\hline $\mathrm{LSD}_{0.05}$ & 1.64 & 3.96 & 1.25 & 2.63 & 48.76 & 1.96 & 1.66 & 4.15 & 8.45 & 0.46 \\
\hline
\end{tabular}

Mean with the same letter in a column are not significantly different each other at $0.05 \%$ probability level. GEN=Genotypes, Maxi.=Maximum, Mini.=Minimum and LSD=Least Significant Difference . Indicators: $50 \mathrm{~F}=$ days to $50 \%$ flowering, $\mathrm{PH}=$ plant height $(\mathrm{cm}), \mathrm{TILL}=$ number of tillers per plant, $\mathrm{PP}=$ number of panicles per plant, $\mathrm{GP}=$ grains per panicle, GYP= grain yield per plant $(\mathrm{g}), \mathrm{PL}=$ panicle length $(\mathrm{cm}), \mathrm{TGW}=$ thousand grain weight $(\mathrm{g}), \mathrm{F}(\%)=$ fertility $(\%)$, and $\mathrm{Yd}=$ yield $\left(\mathrm{t} \mathrm{ha}^{-1}\right)$.

24 Debsharma et al. 


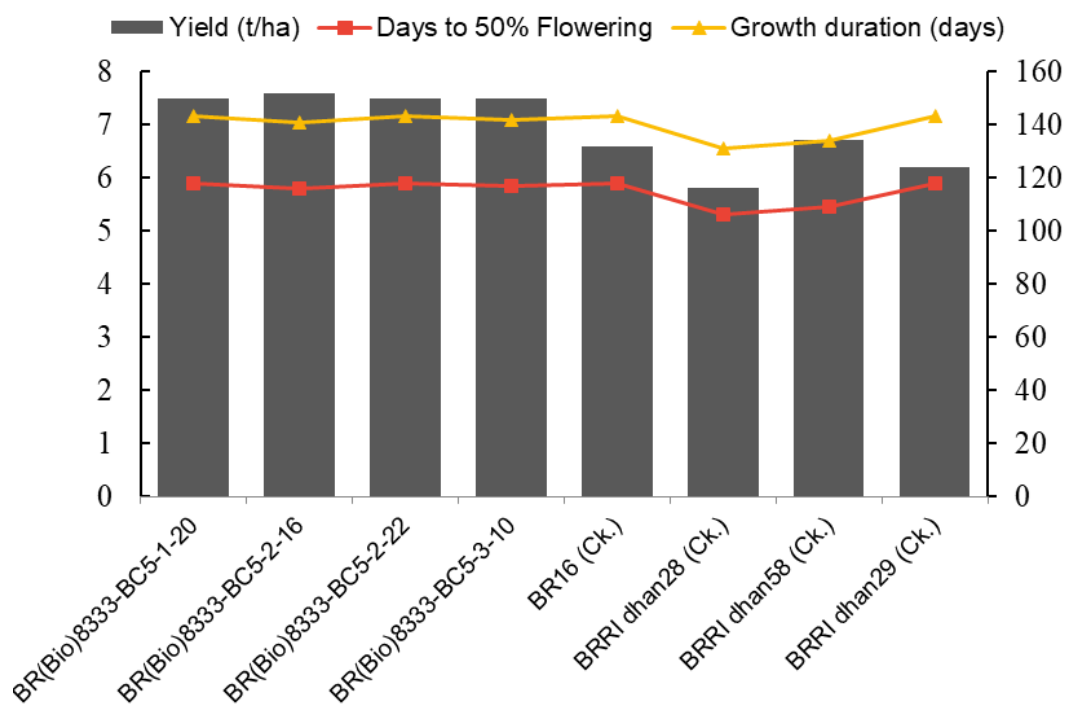

Fig. 1. Comparison between days to $50 \%$ flowering and yield $\left(t \mathrm{tha}^{-1}\right)$ of four selected outstanding genotypes along with four checks.

\section{Correlation analysis}

Out of ten characters, only three viz. days to $50 \%$ flowering, number of panicles per plant and grain yield per plant showed significantly positive correlations with the grain yield (Table 4).

Table 4. Pearson correlation coefficients among the yield contributing traits using genotypes means

\begin{tabular}{|c|c|c|c|c|c|c|c|c|c|}
\hline Particulars & $50 \mathrm{~F}$ & $\mathrm{PH}$ & GYP & TILL & PP & GP & PL & TGW & $\mathrm{F}(\%)$ \\
\hline $\mathrm{PH}$ & -0.283 & 1 & & & & & & & \\
\hline GYP & -0.005 & $-0.431^{* *}$ & 1 & & & & & & \\
\hline TILL & 0.011 & $-0.437^{* *}$ & $0.438^{* *}$ & 1 & & & & & \\
\hline PP & 0.124 & 0.191 & 0.098 & -0.217 & 1 & & & & \\
\hline GP & -0.037 & 0.118 & 0.138 & -0.115 & $0.692^{* *}$ & 1 & & & \\
\hline PL & -0.013 & 0.262 & -0.093 & $0.317^{*}$ & -0.065 & -0.165 & 1 & & \\
\hline TGW & 0.075 & -0.227 & 0.129 & 0.061 & $-0.582^{* *}$ & $-0.371^{* *}$ & -0.026 & 1 & \\
\hline F (\%) & 0.012 & -0.058 & -0.125 & $-0.425^{* *}$ & $0.301^{*}$ & 0.202 & $-0.444^{* *}$ & 0.008 & 1 \\
\hline$Y d$ & $0.606^{* *}$ & -0.124 & $0.393^{* *}$ & -0.242 & $0.301^{*}$ & 0.041 & -0.212 & 0.071 & 0.232 \\
\hline
\end{tabular}


Correlation coefficients between different agronomic traits and grain yield have shown explicitly in Fig 2. Plant height and panicle length had shown negative and non-significant correlation with grain yield. However, grains per panicle, thousand-grain weight and spikelet fertility percentages showed nonsignificant but positive correlation with grain yield. Days to $50 \%$ flowering exhibited negative and non-significant correlations with plant height. Number of tillers per plant showed positive and significant correlation with grain yield per plant and panicle length. Number of panicles per plant exhibited positive and significant correlation with grains per panicle and percent spikelet fertility. Significantly positive correlation was observed between number of panicles per plant and percent spikelet grain fertility.

\section{DISCUSSION}

\section{Genetic variability}

Highly significant genetic variations $(\mathrm{P} \leq 0.01)$ suggested that the studied genotypes had considerable variability for effective selection. The minimum days to $50 \%$ flowering was (105 days) observed in GEN8 (BR8523-36-2-2-6), while the maximum value (120 days) was recorded in GEN1 (BR(Bio)8333-BC5-1-1). Among the tested entries, GEN1 (BR(Bio)8333-
BC5-1-1) showed significant difference from the checks BRRI dhan 28 and BRRI dhan 58. Weiya et al., (2008) also observed variations in heading days among several genotypes and they identified a regulatory gene responsible for this variation. Therefore, it is suggested that these lines should be further studied to confirm their consistent performance. The minimum plant height $(88.6 \mathrm{~cm})$ was recorded in GEN12 (BR8626-10-5-1), while maximum plant height $(116.3 \mathrm{~cm})$ was observed in GEN8 (BR8523-36-2-2-6). Hussain et al., (2005) reported that transplantation time, water and soil condition, planting and sowing method affect plant height in rice. In case of delayed planting in photosensitive rice, plant height is also influenced by different sets of planting time (Biswas et al., 2019).

The minimum tillers per plant (8.0) were produced by rice genotype GEN4 (BR (Bio)8333-BC5-2-22). The GEN9 (Check BR16) produced maximum (14.3) number of tillers per plant. This observation was supported by Zahid et al., (2005), who studied twelve genotypes of coarse rice to check their yield performance and reported highly significant variation for different traits including the number of productive tillers per plant, which is an important yield component in rice.

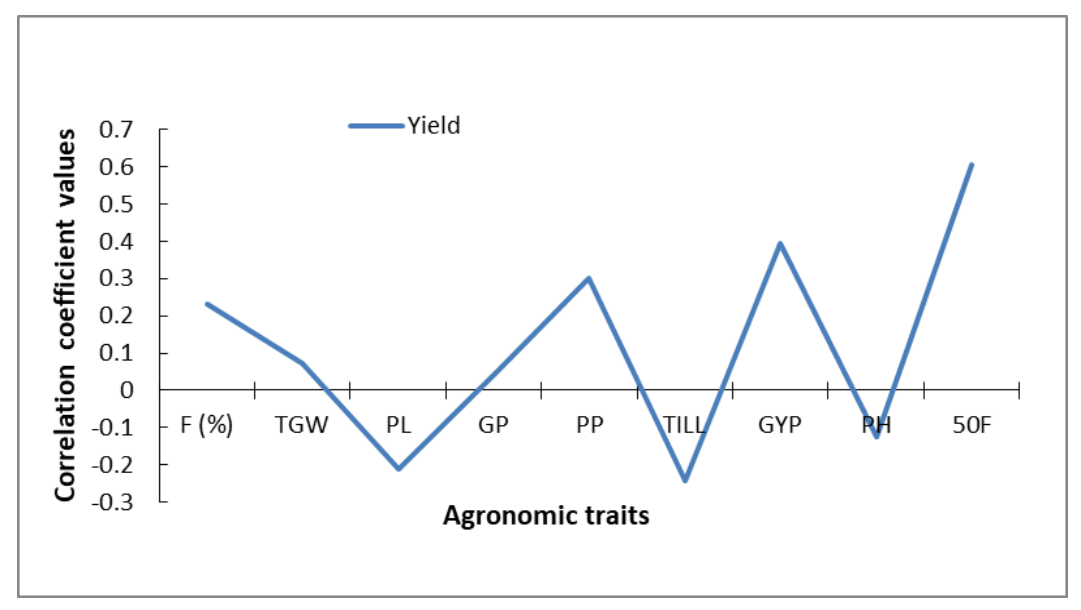

Fig. 2. Correlation coefficients between different agronomic traits and grain yield. 
Minimum number of panicles was found in GEN13 (BR8109-29-2-2-3) and maximum in GEN6 (BRC266-5-1-1-1). The least number of filled grains per panicle was observed in the genotype GEN6 (BRC266-5-1-1-1), while the maximum was in GEN10 (BR7671-37-2-2-37-3P3). Tahir et al., (2002) reported highly significant variation for the grains per panicle for different genotypes.

Minimum grain yield per plant (19.7 g) was recorded in GEN8 (BR8523-36-2-2-6) and maximum $(27.7 \mathrm{~g})$ was recorded in GEN13 (BR8109-29-2-2-3). The shortest panicle length $(21.3 \mathrm{~cm})$ was recorded in GEN12 (BR8626-10$5-1)$ while the longest panicle length $(25.6 \mathrm{~cm})$ in GEN6 (BRC266-5-1-1-1). Ifftikhar et al., (2009) studied genetic variability for various traits and found that this trait is under the genetic control and could be used in the selection process of some desirable traits.

Minimum thousand grain weight (16.1 g) was recorded by GEN10 (BR7671-37-2-2-37-3P3), while maximum (24.7 g) were recorded by GEN9 (check BR16). The findings are in with Tahir et al., (2002), who reported highly significant variation among different traits and observed that these traits are under the control of genotypic difference among the genotypes.

Minimum (69.4) and maximum (85.7) grain fertility percentage were recorded in GEN16 (BRRI dhan29) and in GEN14 (BRRI dhan28), respectively. The highest grain yield $\left(7.58 \mathrm{t} \mathrm{ha}^{-1}\right)$ was recorded by GEN3 (BR(Bio)8333-BC5-2-16), while the lowest (5.18 $\mathrm{t}$ ha-1) was recorded by GEN8 (BR8523-36-2-2$6)$. The same variability was reported by Zahid et al., (2005), who studied twelve genotypes of coarse rice to check their yield performance and reported highly significant variation for different traits. This variation in the grain yield might be due to the environment (Mahapatra, 1993) or the correlation of grain yield per plant with various yield contributing characteristics like; fertility of soil, flag leaf area, number of grains per panicle and grain weight.
Days to $50 \%$ flowering of selected four genotypes were 10-12 and 7-9 days longer than the check varieties BRRI dhan28 and BRRI dhan58, respectively, but similar in days to $50 \%$ flowering with the check varieties BR16 and BRRI dhan29 (Fig 1).

\section{Correlation analysis}

The association between days to $50 \%$ flowering and yield was significant and positive, which means that the late maturing variety produced higher yield. Positive relation of grain yield with panicles per plant was reported by Zahid et al., (2005) and Golam et al., (2011). Zahid et al., (2005) studied 14 genotypes of basmati rice and reported that plant height has negative correlation with yield. Golam et al., (2011) and Kim et al., (1999) reported positive contribution of grains per panicle towards grain yield, which is agreement with the present findings. Eidikohnaki et al., (2013), Haider et al., (2012), Kiani and Nematzadeh (2012), Seyoum et al., (2012), Akinwale et al., (2011) reported the positive association of grain yield with filled grains per panicle. Prasad et al., (2001) observed that a day to $50 \%$ flowering was negatively correlated with plant height, which supported the present study. It was observed that plant height showed significantly negative correlation with grain yield per plant and productive tillers per plant which was supported by Prasad et al., (2001). Rasheed et al., (2002) reported a positive association between fertility percentage and grain yield per plant.

\section{CONCLUSION}

In this study, sixteen Boro rice genotypes showed extensive variability for yield and yield related traits. Correlation analysis revealed that three agronomic traits such as number of panicles per plant (0.301), 50\% flowering (0.606) and grain yield per plant (0.393) had the significantly positive contribution to grain yield. The number of 
panicles per plant showed significantly positive correlation with grains per panicle and spikelet fertility percentages. Though the growth duration of GEN2 (BR(Bio)8333-BC5-120), GEN3 (BR(Bio)8333-BC5-2-16), GEN4 (BR(Bio)8333-BC5-2-22) and GEN5 (BR(Bio) 8333-BC5-3-10) genotypes were longer but possessed 0.79 to $1.75 \mathrm{t} \mathrm{ha}^{-1}$ higher grain yield than the check varieties (BR16, BRRI dhan28, BRRI dhan29 and BRRI dhan58). Therefore, these genotypes were identified as high yielders among all genotypes. The gathered information can be useful for rice research and the selected rice genotypes can be used as potential breeding materials for variety development or use in the breeding program as parents after further evaluations in multilocations in Bangladesh.

\section{AUTHORS' CONTRIBUTION}

SKD and RFD generated idea; SKD, MI and RFD coordinated the experiment/research/ project; SKD, MI, and RFD developed methodology; SKD, MK and MMEA provided scientific insights; SKD and RFD gathered data; SKD and MMEA carried out analysis and synthesis; SKD, MK, and MMEA did the writings all versions of the manuscript; SKD, MK, MMEA and TLA performed critical review and editing; All authors read and approved the final manuscript

\section{ACKNOWLEDGEMENTS}

The authors acknowledge Bangladesh Rice Research Institute, Regional Station, Satkhira for providing funds to accomplish the research work.

\section{DECLARATION OF INTERESTS}

The authors declare that they have no known competing financial interests or personal relationships that could have appeared to influence the work reported in this paper.

\section{REFERENCES}

Akinwale, M G, G Gregorio, F Nwilene , B O Akinyele , S A Ogunbayo , A C Odiyi . 2011. Heritability and correlation coefficient analysis for yield and its components in rice (Oryza sativa L.). African Journal Plant Science, 5(3): 207-212.

Brolley, M. 2015. Rice security is food security for much of the world. Rice Today. International Rice Research Institute (IRRI), DAPO Box 7777, Metro Manila, Philippines. PP. 30-32.

BRRI (Bangladesh Rice Research Institute). 2013. BRRI Annual Research Review Report for 2012-13. Plant Breeding Division, Bangladesh Rice Research Institute, Gazipur-1701, Bangladesh. (data unpublished)

BRRI (Bangladesh Rice Research Institute). 2019. Adhunik Dhaner Chash (Modern Rice Cultivation), 22 $2^{\text {nd }}$ special edition. Bangladesh Rice Research Institute, Gazipur-1701, Bangladesh (in Bangla), PP. 7-9.

Biswas, A, M M Ahmed, T Halder, S Akter, R Yasmeen and M S Rahman. 2019. Photosensitive rice (Oryza sativa L.) varieties under delayed planting as an option to minimize rice yield loss in flood affected T. Aman season. Bangladesh Rice Journal, 23(1), 65-72. https:// doi.org/10.3329/ brj.v23i1.46082.

Eidi-kohnaki, M, G Kiani , G Nematzadeh . 2013. Relationship between morphological traits in rice restorer lines at F3 generation using multivariate analysis. International Journal of Advanced. Biological and Biomedical Research, 1(6): 572-577.

Golam, F, Y H Yin, A Masitah, N Afnierna , N A Majid , N Khalid and M Osman . 2011. Analysis of aroma and yield components of aromatic rice in Malaysian tropical environment. Australian Journal of Crop Science, 5(11): 1318-1325.

Haider, Z, A S Khan, S Zia. 2012. Correlation and path coefficient analysis of yield components in rice (Oryza sativa L.) under simulated drought stress condition. American-Eurasian Journal Agricultural and Environmental Sciences. 12(1): 100-104.

Hussain, S, M Ramzan, M Aslam, Z Manzoor and M E Safdar. 2005. Effect of various stand establishment method on yield and yield components of rice. Proceedings of the International Seminar on Rice Crop. Rice Research Institute, Kala Shah Kau, Lahore, Punjab, Pakistan. October 2-3, 2005. pp. 212220.

Ifftikhar, J, H Khalil , A Bari, S Khan and I Zada. 2009. Genetic variation for yield and yield components in rice. ARPN Journal of Agricultural and Biological Science, 4 (6): 60-64.

Kiani, G, G Nematzadeh . 2012. Correlation and path coefficient studies in F2 populations of rice. Notulae. Scientia. Biologicae, 4(2): 124-127. 
Kabir, M S, M U Salam, A Chowdhury, N M F Rahman, K M Iftekharuddaula, M S Rahman, M H Rashid, S S Dipti, A Islam, M A Latif, A K M S Islam, M M Hossain, B Nessa, T H Ansari, M A Ali and J K Biswas. 2015. Rice vision for Bangladesh: 2050 and beyond. Bangladesh Rice Journal, 19 (2): 1-18. Doi:10.3329/brj.v19i2.28160

Kim, B K, H H Kim, J K Ko and H T Shin. 1999. Effect of planting density and nitrogen levels on growth and yield in heavy panicle weight type of japonica rice. Korean Journal of Crop Science, 44(2): 106-111.

Mahapatra, K C. 1993. Relative usefulness of stability parameters in assessing adaptability in rice. Indian Journal of Genetics and Plant Breeding, 53(4): 435-441.

Nath, N C. 2015. Food security in Bangladesh: Status, challenges and strategic policy options. Paper presented at $19^{\text {th }}$ Biennial Conference of the Bangladesh Economic Association (BAE), 8-10 January, 2015, Dhaka, Bangladesh.

Prasad, B, A K Patwari and P S Biswas. 2001. Genetic variability and selection criteria in fine grain rice (Oryza sativa). Pakistan Journal of Biological sciences, 4(10): 1188-1190.
Rasheed, M S, H A Sadaqat and M Babar. 2002. Correlation and path coefficient analysis for yield and its components in rice (Oryza sativa L.). Asian Journal of Plant Sciences, 1(3): 241-244.

Seyoum, M, S Alamerew, K Bantte. 2012. Genetic variability, heritability, correlation coefficient and path analysis for yield and yield related traits in upland rice (Oryza sativa L.). Journal of Plant Sciences, 7(1): 13-22.

Tahir, M, D Wandan and A Zada. 2002. Genetic variability of different plant yield characters in rice. Sarhad Journal of Agriculture, 18(2): 22-27

Weiya, X, Y Xing, X Weng, Y Zhao , W Tang , L Wang, H Zhou, S Yu, C Xu, X Li and Q Zhang . 2008. Natural variation in Ghd7 is an important regulator of heading date and yield potential in rice, Nature Genetics, 40: 761 - 767. DOI:10.1038/ng.143

Zahid, A M, M Akhtar, M Anwar and A Jamal. 2005. Genotypic and phenotypic, correlation and path analysis in coarse grain rice. Proceedings of the International Seminar on Rice Crop. October 2-3. Rice Research Institute, Kala Shah Kau, Lahore, Punjab, Pakistan. 